\title{
Asymmetric thickness of the left ventricular wall resulting from asynchronous electric activation : a study in dogs with ventricular pacing and in patients with left bundle branch block
}

Citation for published version (APA):

Prinzen, F. W., Cheriex, E. C., Delhaas, T., Oosterhout, van, M. F. M., Arts, M. G. J., Wellens, H. J. J., \& Reneman, R. S. (1995). Asymmetric thickness of the left ventricular wall resulting from asynchronous electric activation : a study in dogs with ventricular pacing and in patients with left bundle branch block. American Heart Journal, 130(5), 1045-1053.

Document status and date:

Published: 01/01/1995

\section{Document Version:}

Publisher's PDF, also known as Version of Record (includes final page, issue and volume numbers)

\section{Please check the document version of this publication:}

- A submitted manuscript is the version of the article upon submission and before peer-review. There can be important differences between the submitted version and the official published version of record. People interested in the research are advised to contact the author for the final version of the publication, or visit the $\mathrm{DOI}$ to the publisher's website.

- The final author version and the galley proof are versions of the publication after peer review.

- The final published version features the final layout of the paper including the volume, issue and page numbers.

Link to publication

\footnotetext{
General rights

- You may freely distribute the URL identifying the publication in the public portal. follow below link for the End User Agreement:

www.tue.nl/taverne

\section{Take down policy}

If you believe that this document breaches copyright please contact us at:

openaccess@tue.nl

providing details and we will investigate your claim.
}

Copyright and moral rights for the publications made accessible in the public portal are retained by the authors and/or other copyright owners and it is a condition of accessing publications that users recognise and abide by the legal requirements associated with these rights.

- Users may download and print one copy of any publication from the public portal for the purpose of private study or research.

- You may not further distribute the material or use it for any profit-making activity or commercial gain

If the publication is distributed under the terms of Article $25 \mathrm{fa}$ of the Dutch Copyright Act, indicated by the "Taverne" license above, please 


\title{
Asymmetric thickness of the left ventricular wall resulting from asynchronous electric activation: A study in dogs with ventricular pacing and in patients with left bundle branch block
}

\author{
Frits W. Prinzen, $\mathrm{PhD},{ }^{\mathrm{a}}$ Emile C. Cheriex, $\mathrm{MD},{ }^{\mathrm{b}}$ Tammo Delhaas, $\mathrm{MD}, \mathrm{PhD},{ }^{\mathrm{a}}$ \\ Matthijs F. M. van Oosterhout, MD, ${ }^{a}$ Theo Arts, $\mathrm{PhD},{ }^{c}$ Hein J. J. Wellens, $\mathrm{MD}, \mathrm{PhD},{ }^{b}$ and \\ Robert S. Reneman, $\mathrm{MD}, \mathrm{PhD}^{\mathrm{a}}$ Maastricht, The Netherlands
}

\begin{abstract}
Various kinds of abnormal, asynchronous electric activation of the left ventricle (LV) decrease mechanical load in early versus late activated regions of the ventricular wall. Because myocardium usually adapts its mass to changes in workload, we investigated by echocardiography whether regional differences in wall thickness are present in two kinds of asynchronous electric activation of different origin and conduction pathway: epicardial ventricular pacing in dogs and left bundle branch block (LBBB) in patients. In six dogs, 3 months of epicardial LV pacing at physiologic heart rates decreased the thickness of the early activated anterior wall by $20.5 \pm 8.1 \%$ without significantly changing LV cavity area and septal thickness. In a retrospective study of 228 LBBB patients, the early activated septum was significantly thinner than the late activated posterior wall. The asymmetry most pronounced was as large as $10 \%$ in 28 patients with LBBB and paradoxic septal motion. No difference in regional wall thickness was present in 154 control patients. In conclusion, chronic asynchronous electric activation in the heart induces redistribution of cardiac mass. This redistribution occurs in hearts, which differ in impulse conduction pathway, disease, and species and is characterized by thinning of early versus late activated myocardium. (AM HEART J 1995;130:1045-53.)
\end{abstract}

Mass and composition of cardiac muscle are known to adapt to changes in hemodynamic load. ${ }^{1,2}$ Global and regional adaptations are known to occur such as

From the Departments of aphysiology, ${ }^{b}$ Cardiology, and ${ }^{\mathrm{c} B i o p h y s i c s,}$ Cardiovascular Research Institute Maastricht, University of Limburg and University Hospital.

Supported by grant 900-516-91 from the Netherlands Organization for Scientific Research and the Bakken Research Center.

Received for publication Nov. 28, 1994; accepted May 12, 1995

Reprint requests: Frits W. Prinzen, PhD, Department of Physiology, Cardiovascular Research Institute Maastricht, University of Limburg, P.O. Box 616, 6200 MD Maastricht, The Netherlands.

Copyright @ 1995 by Mosby-Year Book, Inc.

$0002-8703 / 95 / \$ 5.00+0 \quad \mathbf{4} / \mathbf{1} / \mathbf{6 6 5 3 4}$ in the left ventricle following myocardial infarction. ${ }^{3}$ Intraventricular conduction disorders, ventricular premature beats or tachycardia, and ventricular pacing are associated with abnormal asynchrony of electrical activation because the conduction of the electrical wavefront initially occurs through slowly conducting myocardial muscle cells rather than through the Purkinje system. The asynchronous electrical activation induces changes of wall motion such as paradoxical bulging during systole and shortening during relaxation. ${ }^{4-6}$ It has been demonstrated in dog hearts that segment shortening is more pronounced farther rather than closer to the pacing site. ${ }^{9}$

In previous studies, we have related these changes in wall motion to regional mechanical performance. It was demonstrated that during ventricular pacing fiber length at the onset of the ejection phase, fiber shortening and contractile work during the ejection phase (the time integral of fiber shortening $\times$ fiber stress), and blood flow and oxygen consumption are reduced in early-activated regions and increased in late-activated regions..$^{7,8}$ On the basis of these findings, it was concluded that asynchronous electrical activation causes redistribution of mechanical load within the ventricular wall. A similar redistribution of mechanical load may also be present in left bundle branch block (LBBB) because in the septum, which is activated relatively early in patients with LBBB, wall motion ${ }^{6,10}$ and blood flow have been reported to be reduced ${ }^{11,12}$ despite the absence of coronary artery obstruction. These data support the idea that asynchronous electrical activation of various origin generally induces a decrease of mechanical load in early-activated regions and an increase in late-activated regions, irrespective of the presence of cardiac disease. 


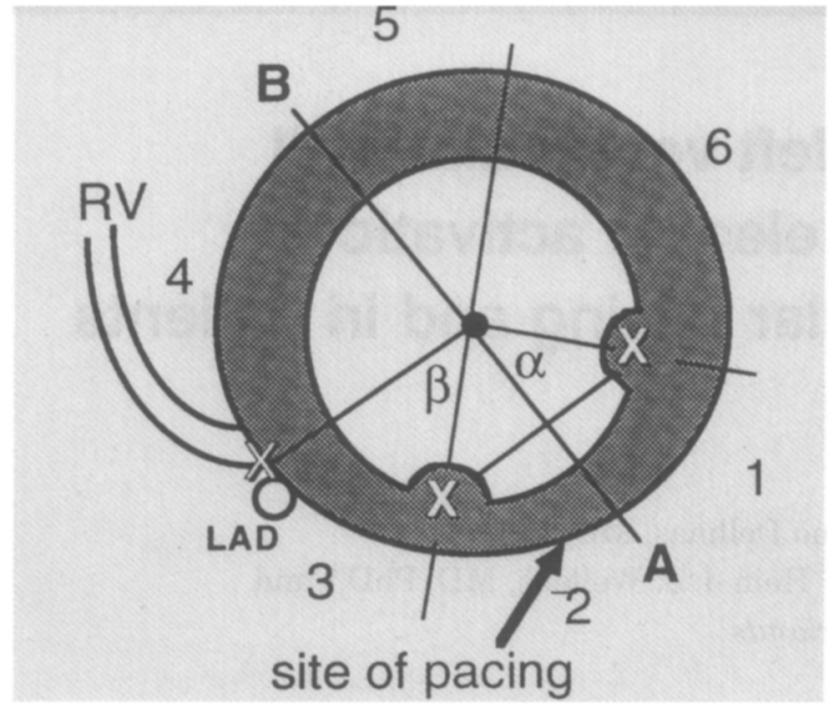

Fig. 1. Division of ventricular cross-section on two-dimensional image into sectors according to three anatomic landmarks: centers of papillary muscle attachments and of attachment of right ventricle to left ventricle at anterior wall $(X)$. Line $A-B$ is perpendicular to line connecting papillary muscle landmarks. $\alpha$ and $\beta$ are sector angles of sectors 1 and 3, respectively. Sector angles of sectors 1, 2, and 5 were equal. $R V$, Right ventricle; $L A D$, left anterior descending artery.

This study was conducted to investigate whether regional differences in mechanical load, as induced by asynchronous electrical activation, are related to asymmetrical changes in left ventricular wall thickness. In a prospective study of dogs, regional ventricular wall thickness was determined before and at various time intervals after induction of asynchronous electric activation by epicardial left ventricular pacing. Regional ventricular wall thickness was assessed by means of two-dimensional echocardiography. In addition, it was investigated retrospectively whether systematic asymmetry in left ventricular wall thickness is also present in a relatively heterogeneous population of patients with LBBB. Because the conduction pathway during epicardial left ventricular pacing is approximately opposite to that of LBBB, the asymmetry is also expected to be opposite. If this is the case, it indicates that in the heart the sequence of electric activation is an important determinant of local wall thickness, irrespective of species or cardiac disease.

\section{METHODS}

Prospective study in dogs. In the present study of dogs we used pacing at the epicardium of the free wall of the left ventricle. This induces an impulse conduction pattern approximately opposite to that during LBBB: early activation of the left ventricular free wall and late activation of the septum. This position of the pacing electrode was chosen because previous studies showed that pacing from this site resulted in a pronounced asynchrony of ventricular activation..$^{13}$ Moreover, with this electrode position both earlyand late-activated regions could be visualized in one echocardiographic cross-section.

Implantation procedure. In eight mongrel dogs the pacemaker and pacing electrodes were implanted during a sterile surgical procedure. A Medtronic 4057 (Minneapolis, Minn.) endocardial screw-in lead was inserted through the wall of the atrial appendix into the right atrial cavity and screwed into the endocardial surface of the right atrial wall. The ventricular lead was a Medtronic 6917A-35T sutureless lead (four dogs) or a Medtronic 4951M unipolar myocardial lead (four dogs). These leads were attached to the epicardium of the free wall of the left ventricle, $1 \mathrm{~cm}$ below the base, by using their screw-in device. A pacemaker (Medtronic Synergist H7027, H7071, or Elite II) was implanted subcutaneously over the left lower thoracic region, and the leads were guided subcutaneously toward the pacemaker pocket. After fixing the leads to the pacemaker and checking proper electric contact, the pacemaker was positioned into its subcutaneous pocket and the skin over the pocket was closed. The animals were allowed to recover from anesthesia and the surgical procedure while the pacemaker was not functioning.

Ventricular pacing was started approximately 2 weeks after implantation. Pacing was performed in the DDDmode so the heart was paced at its own sinus rhythm as long as sinus rhythm was below the maximal pacing rate of the pacemaker ( 175 beats $/ \mathrm{min}$ ). The AV stimulation interval was $25 \mathrm{msec}$ to ensure that the whole ventricle was activated from the site of the pacing electrode rather than through conduction through the $\mathrm{AV}$ node.

Measurement of ventricular wall thickness. Two-dimensional echocardiographic images of the left ventricle were recorded on videotape with a Hewlett-Packard Ultrasound System (77020A; Andover, Mass.) with a $3.5 \mathrm{MHz}$ transducer (21206A). One week before and 1, 2, and 3 months after onset of pacing, recordings were made while the animals were conscious. Short axis cross-sectional images were made, taking care that they were as circular as possible and that the tip of the papillary muscles and the pacing lead were visible.

Measurements, in an unblinded fashion, were performed on videoprints ( $10 \times 15 \mathrm{~cm}$ by videoprinter) of enddiastolic images. For each image, endocardial and epicardial contours were drawn on overhead sheets. In a first step of the analysis, the cross-section of the prepacing images was divided into six sectors according to the following anatomic landmarks: the centers of the anterior and posterior papillary muscle attachments and the center of the anterior attachment of the right ventricular wall to the left ventricular wall (marked as crosses in Fig. 1). The center of the cavity was positioned between line A-B (Fig. 1), perpendicular to the line connecting the two papillary muscle landmarks. The anterior wall was divided into three sectors by drawing lines from the center of the cavity to the three anatomic landmarks. The sector between the two 


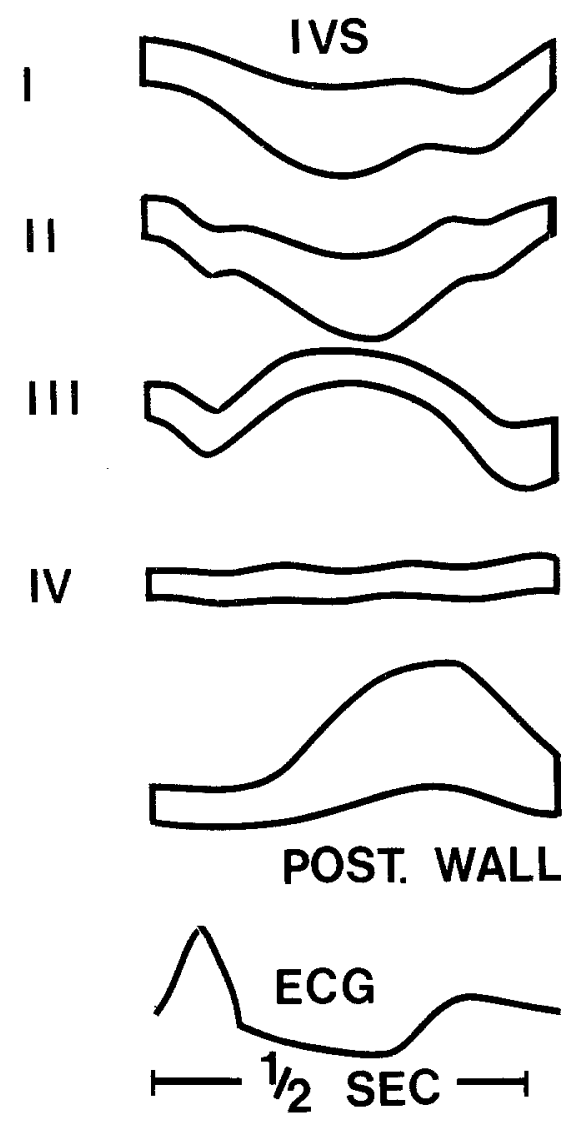

Fig. 2. Schematic composite ofM-mode echocardiographic images. Four forms of interventricular septal (IVS) motion are indicated and pattern of posterior wall motion in LBBB. Systolic paradoxic septal motion was defined as rightward motion in combination with thinning of septum during systole (pattern III). Patients in group 1 had IVS pattern I or II.

papillary muscles was divided into two equal sectors with line A-B. Sector 5 was defined to be exactly opposite to sector 2 , and sector 4 spanned the septal wall between sector 5 and sector 3 .

On the images obtained at the time intervals during ventricular pacing, the three anatomic landmarks were localized by optimal superposition of templates of the endocardial (papillary muscles) and epicardial contours (RVLV attachment) of the prepacing image of a particular animal. Thereafter, the ventricular cross-section of the images of paced beats was also divided into six sectors, as described earlier for the prepacing images. Sector 6 was usually incomplete in the echocardiographical images. In all animals the pacing lead was located in wall sector 2 . Sectors 1 and 3 were adjacent and sector 5 was the most remote region, located in the ventricular septum.

The area of the wall sectors (sectors 1,2 , and 3 , including papillary muscle) and the area of the ventricular cavity was determined by planimetry. The angles spanning sectors 1 and $2(\alpha)$ and sector $3(\beta)$ were measured. From these values the sector angles 1 through 5 were determined to be $\alpha, \alpha, \beta, 180^{\circ}-2 \alpha-\beta$, and $\alpha$, respectively (Fig 1). Av-

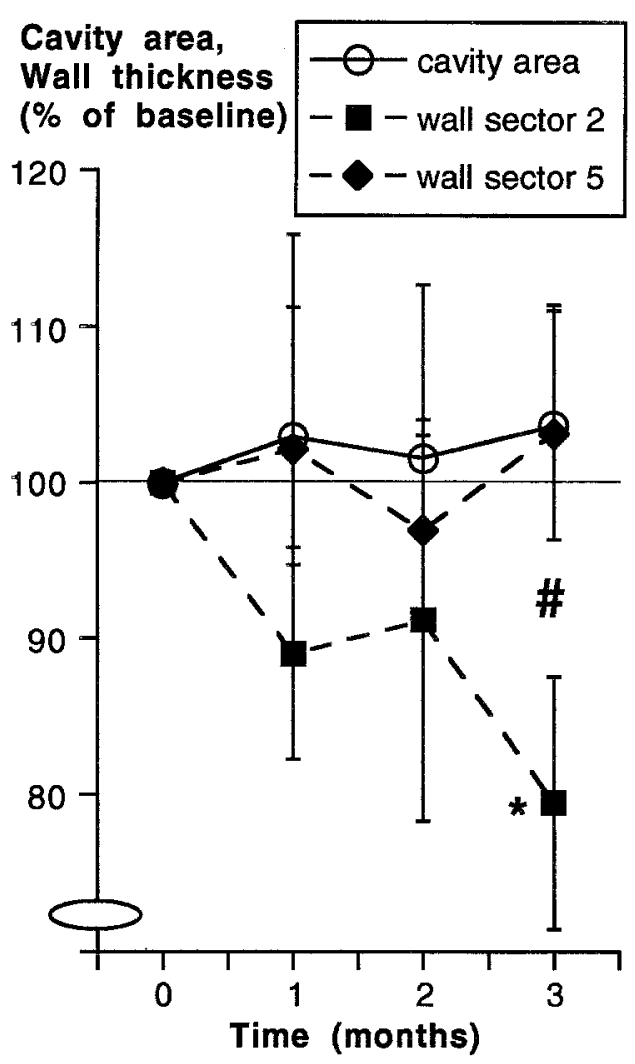

Fig. 3. Time course of changes in cavity area and wall thickness in two sectors of ventricular wall in paced dogs. Mean values \pm SD are presented. Numbers of sectors refer to division of left ventricular cross-section as depicted in Fig. 1. ${ }^{*}, p<0.05$ compared with time $=0 ; \#, p<0.05$ between sector 2 and sector 5 .

erage wall thickness (h) of a particular sector was calculated as: $\sqrt{\mathrm{h}=\left(\mathrm{A}_{\text {cav }}+360 \mathrm{~A}_{\mathrm{wall}} / \phi\right) / \pi}-\sqrt{\mathrm{Acav} / \pi}$, where Acav = left ventricular cavity area, $A_{\text {wall }}=$ wall sector area, and $\phi=$ sector angle. With these measurements an indication is obtained about the size of the ventricular cavity volume and of the length and mass of the various wall sectors. By using relatively large wall sectors, inaccuracies in determining the endocardial and epicardial boundaries at a particular site were averaged out. Intraobserver variability was $5.7 \%$, and interobserver variability was $5.8 \%$. Wall thickness during pacing was expressed as a percentage of prepacing wall thickness.

\section{Retrospective study in LBBB patients}

Selection of patients. From our echocardiographic database containing 14,000 patients, the following patients were selected: (1) 228 patients with LBBB but without paradoxic wall motion (LBBB group, 129 men and 99 women aged $63.8 \pm 14.0$ years); (2) 28 patients with LBBB whose echocardiogram revealed systolic paradoxic wall motion of the ventricular septum, indicating pronounced asynchronous electric activation ${ }^{14}$ (pLBBB group, 13 male and 15 female, age $61.1 \pm 12.6 \mathrm{yr}$ ) (the definition of paradoxic systolic septal wall motion is illustrated in Fig. 2 [pattern III]); and (3) an age-matched "control" group of 


\section{Wall thickness (\% of baseline)}

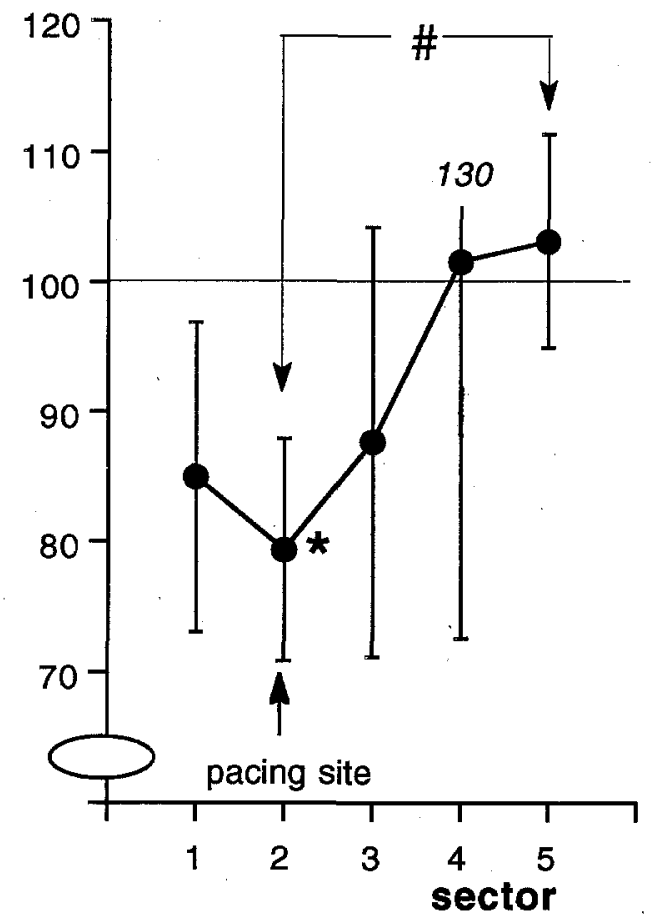

Fig. 4. Changes in regional wall thickness in five sectors of left ventricular wall in paced dogs 3 months after onset of experiment. Mean values \pm SD are presented. Numbers of sectors refer to division of left ventricular cross-section as depicted in Fig. 1.

154 patients ( 69 men and 85 women aged $61.6 \pm 7.8$ years). This group consisted of patients who had echocardiograms made for diagnostic purposes. No abnormalities were found in these patients, and none of the patients had a history of cardiovascular disease such as myocardial infarction, ventricular hypertrophy, or conduction disturbances.

Table I describes the major cardiac characteristics of the three groups. There were no myocardial infarctions in the control group by definition but a small number of mitral valve and tricuspid valve insufficiencies. In the LBBB group, 53 of 228 patients had a history of myocardial infarction. The majority of the infarcts were located in the inferior wall, often combined with either the posterior or the anterior wall. Of all LBBB patients, more than half had mitral insufficiency and a quarter had tricuspid insufficiency. In 18 patients, mitral annulus calcifications were noted. The percentage of infarctions and valvular abnormalities in the pLBBB group and the LBBB group was similar (Table I).

Echocardiography. Echocardiographic cross-sectional projections were made with a phased-array echocardiographic Doppler system (Hewlett-Packard Sonos 500 and 1000). This system uses a 3.5 or $2.5 \mathrm{MHz}$ phased
Table I. Cardiac abnormalities in three patient groups

\begin{tabular}{|c|c|c|c|c|c|c|}
\hline & \multicolumn{2}{|c|}{$\begin{array}{c}\text { Control } \\
(n=154)\end{array}$} & \multicolumn{2}{|c|}{$\begin{array}{c}L B B B \\
(n=228)\end{array}$} & \multicolumn{2}{|c|}{$\begin{array}{l}p L B B B \\
(n=28)\end{array}$} \\
\hline & $n$ & $\%$ & $n$ & $\%$ & $n$ & $\%$ \\
\hline \multicolumn{7}{|l|}{ Infarction } \\
\hline Total & 0 & 0 & 53 & 23 & 10 & 34 \\
\hline Inferior & 0 & 0 & 27 & 12 & 7 & 24 \\
\hline Anterior & 0 & 0 & 7 & 3 & 0 & 0 \\
\hline Posterior & 0 & 0 & 7 & 3 & 0 & 0 \\
\hline Combination & 0 & 0 & 15 & 6 & 3 & 10 \\
\hline \multicolumn{7}{|l|}{ Valvular } \\
\hline Mitral insufficiency & 13 & 8 & 135 & 58 & 14 & 48 \\
\hline Mitral valve prolapse & 10 & 6 & 7 & 3 & 1 & 3 \\
\hline Tricuspid insufficiency & 9 & 6 & 66 & 29 & 10 & 34 \\
\hline Aortic insufficiency & 2 & 1 & 32 & 14 & 4 & 14 \\
\hline Aortic stenosis & 0 & 0 & 4 & 2 & 0 & 0 \\
\hline
\end{tabular}

array transducer. Data were recorded on a recorder strip chart at a speed of $25 \mathrm{~mm} / \mathrm{sec}$. Standard echocardiographic views were recorded on videotape. All measurements were performed with the patient in the recumbent position. Mmode measurements were made on cross-sectional images at the tips of the mitral valve according to the recommendations of the American Society of Echocardiography ${ }^{15}$ by experienced echocardiographers. The following parameters were determined: end-diastolic and end-systolic thickness of the posterior wall of the left ventricle (PWEDT and PWEST, respectively) and of the interventricular septum (IVSEDT and IVSEST, respectively), and end-diastolic and end-systolic diameters of the left ventricular cavity (LVEDD and LVESD, respectively).

To assess whether differences in wall thickness between the groups were related to differences in cavity volume, the end-diastolic thickness of the posterior and septal walls was normalized to left ventricular end-diastolic diameter. To assess asymmetry in ventricular wall thickness, the ratio of end-diastolic thickness of the ventricular septum and the posterior wall was calculated. Total left ventricular wall mass (LV mass) was estimated according to the diameter-cubed formula of Devereux and Reichek ${ }^{16}: \mathrm{LV}$

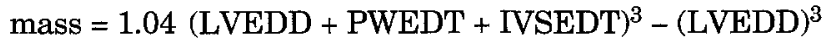
- 13.6 where LV mass is left ventricular mass (grams), and echocardiographical dimensions are expressed in centimeters.

Statistics. Differences between the groups were evaluated for statistical significance with analysis of variance and Fisher's LSD test using the Superanova software package on an Apple Macintosh (Cupertino, Calif.) computer. Data are presented as mean values $\pm \mathrm{SD}$.

\section{RESULTS}

Prospective study in dogs. During ventricular pacing at the epicardium of the LV wall, the width of the QRS complex increased from $41 \pm 8$ msec during sinus rhythm to $119 \pm 10 \mathrm{msec}$. This increase was independent of the duration of pacing. 
Table II. Global left ventricular dimensions in three patient groups

\begin{tabular}{lccl}
\hline \multicolumn{1}{c}{ Group } & Control $(n=154)$ & $L B B B(n=228)$ & $p L B B B(n=28)$ \\
\hline End-diastolic LV diameter $(\mathrm{mm})$ & $45.07 \pm 4.46$ & $52.96 \pm 8.42 \ddagger$ & $57.71 \pm 8.68 \ddagger$ \\
End-systolic LV diameter $(\mathrm{mm})$ & $27.86 \pm 5.32$ & $37.75 \pm 11.91 \ddagger$ & $46.57 \pm 10.11 \ddagger \S$ \\
Systolic LV diameter change $(\mathrm{mm})$ & $17.21 \pm 4.61$ & $15.21 \pm 8.44 \dagger$ & $11.14 \pm 3.39 \ddagger \S$ \\
Calculated total LV mass $(\mathrm{gm})$ & $155.0 \pm 32.8$ & $227.5 \pm 67.7 \ddagger$ & $244.7 \pm 74.5 \div \S$ \\
\hline
\end{tabular}

Values are mean $\pm \mathrm{SD}$.

$\dagger p<0.01$ compared with control group.

$\ddagger p<0.001$ compared with control group.

$\$ p<0.05$ compared with LBBB group.

During the 3 months of pacing, no consistent changes were observed in the angles of the wall sectors. Left ventricular cavity area tended to increase $(p=0.10$, Fig. 3). Mean wall thickness per sector decreased in sector 2 (close to the pacing electrode) and slightly increased in the remote sector 5 (Fig. 3). The decrease in wall thickness in sector $2(20.5 \% \pm 8.1 \%)$ was statistically significant after 3 months of pacing $(p<0.05)$. The difference between the changes in wall thickness in the early-activated sector 2 and the late-activated sector 5 was consistent $(22.8 \% \pm 7.4 \%$, $p<0.01$ ). Fig. 4 illustrates that wall thickness decreased in the sector where the pacing electrode was positioned (sector 2) and also, to a lesser extent, in areas 1 and 3. A rather variable change in wall thickness was observed in sector 4 .

Retrospective study in patients. The left ventricular end-diastolic and end-systolic diameters were smaller in the control than in the LBBB group (Table II). In the pLBBB group, end-systolic cavity diameter was significantly larger than in both other groups. The decrease of left ventricular diameter during systole was less in the two groups of LBBB patients than in the control group, and smaller in the pLBBB than in the LBBB group. In both LBBB groups, estimated total left ventricular mass was larger than in the control group. The increase in mass was most pronounced in the pLBBB group (Table II).

In the control group, thickness of septum and posterior wall were not significantly different ( $8.50 \pm 0.95 \mathrm{~mm}$ vs $8.54 \pm 0.93 \mathrm{~mm}$, respectively; Fig. 2). In the LBBB patients, the early-activated septum was thinner than the late-activated posterior left ventricular wall $(9.10 \pm 1.21 \mathrm{~mm}$ vs $9.33 \pm 1.03$ $\mathrm{mm}$, respectively; $p=0.012$ ). A more pronounced difference between thickness of septum and posterior wall was observed in patients with pLBBB: $8.25 \pm 1.38 \mathrm{~mm}$ vs $9.14 \pm 0.97 \mathrm{~mm}$, respectively $(p=0.017$, Fig. 5$)$. In the LBBB group the septum was thicker than in the control and pLBBB groups. The posterior wall was thicker in both LBBB groups than in the control group (Fig. 5). However, the ratio of septal wall thickness to cavity diameter was $8 \%$ and $24 \%$ smaller in the LBBB and pLBBB patients than in the control patients, respectively (Fig. 6). The ratio of posterior wall thickness to cavity diameter was also significantly smaller in both LBBB groups than in the control group, but the differences were smaller (Fig. 6). These data demonstrate that, as compared with control patients, left ventricular cavity diameter in LBBB patients is increased more than left ventricular mass, indicating eccentric hypertrophy in LBBB patients.

The degree of asymmetry of wall thickness was expressed as the ratio of septal to posterior wall thickness (Fig. 7). This ratio was $1.00 \pm 0.06$ in the control group. In $25 \%$ and $45 \%$ of the LBBB and pL$\mathrm{BBB}$ patients, respectively, the septum was thinner than the posterior wall, whereas in $9 \%$ and $4 \%$ of the patients the septum was thicker than the posterior wall, respectively. Consequently the ratio of septal to posterior wall was significantly smaller than unity in the LBBB patients $(0.98 \pm 0.08, p=0.015)$ and in the pLBBB patients $(0.90 \pm 0.12, p<0.001 ;$ Fig. 7$)$. This asymmetry in ventricular wall thickness did not depend on the presence of myocardial infarction: the anterior to posterior wall thickness ratio did not change when the patients with myocardial infarction were excluded from the analysis $(0.97 \pm 0.11$ in the LBBB group and $0.91 \pm 0.13$ in the pLBBB group, Fig. 7).

\section{DISCUSSION}

In this study it was found that during long-lasting ventricular pacing at physiologic heart rate in normal canine hearts, the early-activated free wall of the left ventricle became thin relative to the late-activated septal wall. In eccentrically hypertrophied hearts of patients with LBBB, the early-activated septal wall was thinner than the late-activated posterior wall. These findings indicate that chronic asynchronous electric activation of the left ventricle induces asymmetry of left ventricular wall thickness. 


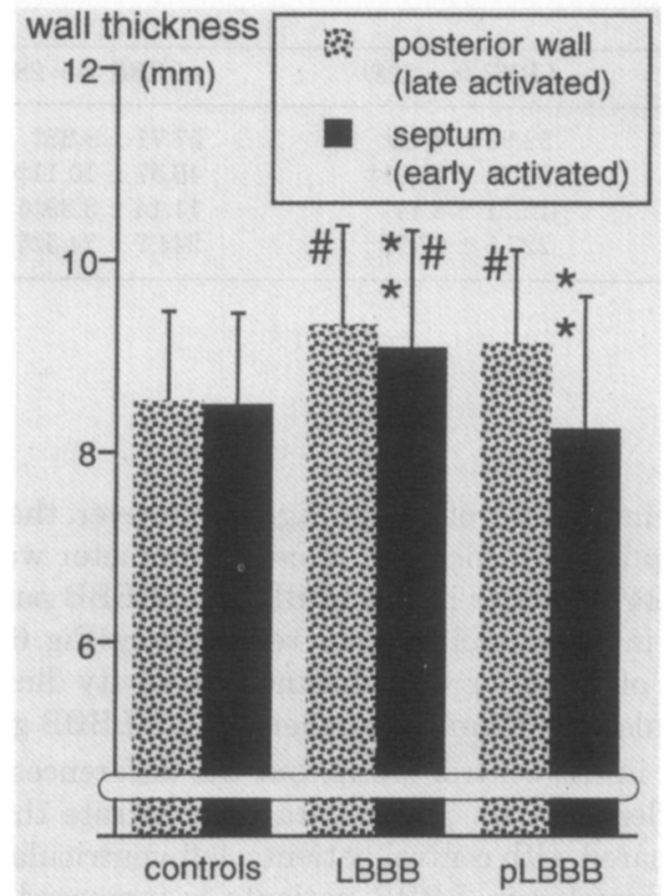

Fig. 5. End-diastolic thickness of posterior wall and ventricular septum in three patient groups. LBBB and pLBBB indicate groups of patients with LBBB (group 1) and with LBBB and systolic paradoxic wall motion, respectively. Definition of systolic paradoxic wall motion is depicted in Fig. 2. **, $p<0.01$ between posterior wall and septum of same group; \#, $p<0.05$ compared with corresponding wall thickness in control group.

The approximatelyopposite sequence of electric activation in the paced dogs and LBBB patients coincided with an opposite asymmetry: in both studies the early-activated region was thinner than the late-activated one.

Because ventricular activation was made asynchronous on purpose in the prospective dog study and the dogs had no cardiac abnormalities, the relation between the asynchrony of electric activation and asymmetry of ventricular wall thickness is most convincing. In the LBBB patients, concomitant disease may have influenced wall thickness. However, in mitral insufficiency or hypertension one would expect a uniform increase in wall thickness because of the global increase in pump load. Although myocardial infarction may result in regional wall thinning, it is unlikely that the nonuniformity in ventricular wall thickness found in the whole group of LBBB patients is from LBBB caused by myocardial infarction: exclusion of data from patients with myocardial infarction did not change the degree of asymmetry of wall thickness. Therefore as in chronically paced dogs, the asymmetry of ventricular wall

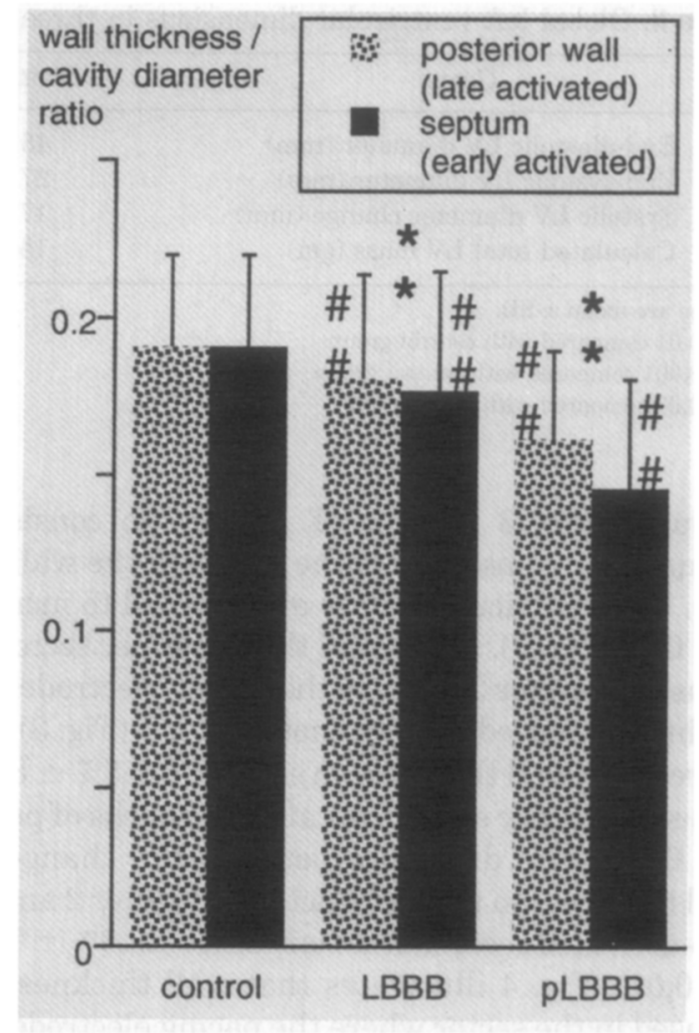

Fig. 6. Ratio of wall thickness and left ventricular cavity diameter at end-diastole in three patient groups. **, $p<0.01$ between posterior wall and septum of same group; $\# \#, p<0.01$ compared with the ratio of control group.

thickness in patients with LBBB is most likely caused by the asynchronous electric activation of the ventricular wall. The relevance of these findings is that asymmetry in wall thickness may occur because of asynchronous electric activation of various kinds and different conduction pathways. Furthermore, they indicate that the effect of asynchronous electric activation on regional wall thickness is large enough to be detected in a heterogeneous group of patients.

Possible explanation for the change in regional wall thickness. The observation that during asynchronous electric activation early-activated regions are consistently thinner than late-activated regions seems related to the difference in workload between these regions. In previous experiments with acute ventricular pacing, we demonstrated that fiber shortening, mechanical work, and blood flow were lower in early- rather than in late-activated regions. $7,8,13$ Therefore the asymmetry in wall thickness during longlasting asynchronous electric activation may be explained by local adaptation of myocardial mass to local differences in mechanical load. Evidence for such local control of myocardial growth is found in 
several other studies. After experimental systemic hypertension, hypertrophy is found in the left ventricle but not in the right ventricle. ${ }^{17}$ Also, stretching induces a hypertrophic response in isolated myocytes. ${ }^{18,19,20}$ The findings this study indicate that different degrees of wall thickness can be induced within one ventricle.

The exact stimulus for cardiac hypertrophy or atrophy is not well understood. Both pressure and volume overload are known to increase myocardial muscle mass. From this kind of observation, fiber stress and stretch are regarded to be involved in inducing hypertrophy. ${ }^{21} \mathrm{It}$ is interesting to note that in our previous studies ventricular pacing induced substantial changes in local end-diastolic fiber length and systolic shortening but hardly any changes in fiber stress. ${ }^{8}$ In recent simulations in a mathematic model the role of various factors on the origin of myocardial growth was investigated. The results indicate that, in addition to global contractility, regional fiber shortening and maximal stretch during the cardiac cycle are important determinants of muscle growth and fiber orientation through feedback control. In these simulations feedback through fiber stress was not a compelling condition for such control..$^{22}$ Extrapolation of these data to the situation during asynchronous electric activation suggests that regional differences in fiber stretch and systolic shortening ${ }^{7,8,13}$ may be held responsible for the local differences in wall thickness in the patients with LBBB and in the chronically paced dogs.

The data from the dog study (Figs. 3 and 4) demonstrate that reduction in wall thickness occurs in the segment where the pacing electrode is located and, to a lesser extent, in the adjacent wall sectors, which are activated slightly later than the former sector. As a consequence, ventricular pacing may induce atrophy in a considerable part of the ventricular wall around the site of stimulation and hypertrophy in a region opposite to the stimulation site. The gradual transition from atrophy in the earliest activated anterior wall sector to hypertrophy in the latest activated septal sector is in keeping with the hypothesis that structural adaptations of the myocardium are related to the sequence of electric activation. This hypothesis is supported by the observation that in the patients with the most abnormal wall motion patterns (the pLBBB group, indicating a more asynchronous activation) a larger fraction showed asymmetry in left ventricular wall thickness.

The asymmetry in wall thickness was more pronounced in the paced dogs than in the LBBB patients. This difference may be from factors causing

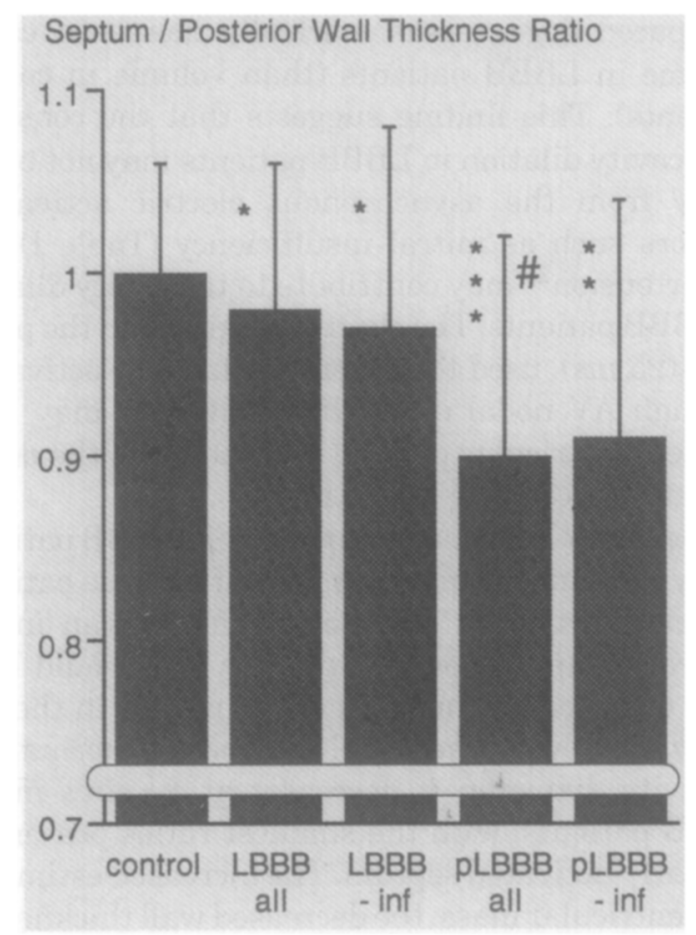

Fig. 7. Ratio of end-diastolic thickness of septum and posterior wall in three patient groups. ***,***, $p<0.05$, $<0.01$, and $<0.001$ compared with control group, respectively; \#, $p<0.05$ compared with corresponding LBBB group. Inf, Same group after exclusion of patients with infarction.

underestimation in the patient study. Because of the prospective design of the dog study, we were able to relate wall thickness of a particular region during pacing to the thickness of the same region before onset of pacing. In contrast, in the retrospective patient study ventricular wall thickness was compared at the two standard sites used in diagnostic echocardiography and without knowledge of their thickness before onset of the conduction abnormality. Moreover, the variability in cardiac anatomy in the LBBB patients can be expected to be larger than in the control patients and in the dogs because of the other concomitant cardiovascular diseases in the LBBB patients. Also, the variability in anatomy of the left bundle branch ${ }^{23}$ and the variability in wall motion patterns in patients with $\mathrm{LBBB}^{6,24}$ probably led to interindividual differences in location and extent of the decrease in wall thickness. Therefore relative changes in wall thickness, as large as observed in the dogs with ventricular pacing, might have occurred in the earliest and latest activated region of each patient with LBBB.

Another difference between the two studies was slightly increased left ventricular cavity volume in 
the paced dogs versus markedly increased cavity volume in LBBB patients (than volume in control patients). This finding suggests that the considerable cavity dilation in LBBB patients may not be entirely from the asynchronous electric activation. Factors such as mitral insufficiency (Table I) and hypertension ${ }^{25}$ may contribute to the cavity dilation in LBBB patients. The short AV interval in the paced dogs $(25 \mathrm{~ms})$, used to prevent ventricular activation through AV nodal conduction, however, may have limited ventricular preload and therefore the development of eccentric hypertrophy.

The larger left ventricular cavity in LBBB patients likely explains the observation that in these patients the early-activated septum is thicker than in the control group, although a thinner wall would have been expected on the basis of the results in the dog study. However, when wall thickness is normalized to cavity diameter, it decreases at all sites in the LBBB patients, with the smallest ratios present in the early-activated septum. The increased estimated left ventricular mass, the decreased wall thickness to cavity diameter ratio, and the regional difference in this ratio illustrate that these patients have asymmetric eccentric hypertrophy.

Possible clinical implications. Regional wall motion abnormalities have also been described in patients with Wolff-Parkinson-White syndrome, ${ }^{26}$ ventricular tachycardia, ${ }^{27}$ and patients with a ventricular pacemaker. ${ }^{10}$ Our previous studies indicate that such wall motion abnormalities indicate redistribution of mechanical load within the ventricular wall. ${ }^{7}$ Moreover, we demonstrated that the extent of local fiber shortening is related to the time interval between local electric activation and the maximal rate of rise of left ventricular pressure. This relation was independent of the site of pacing ${ }^{13}$ and thus independent of the pattern of intraventricular impulse conduction. Therefore it is most likely that any kind of asynchronous electric activation is associated with nonuniform distribution of mechanical load. Because this study supports a relation between regional mechanical load and adaptation in wall thickness during ventricular pacing and LBBB, it seems justified to suggest that asymmetry of wall thickness may also be present in patients with the previously mentioned forms of impulse conduction disturbances.

These data seem of special interest for the application of ventricular pacing in the treatment of hypertrophic obstructive cardiomyopathy. Ventricular pacing of these hearts with extremely thickened septa results in promising improvements. Immediately after onset of pacing significant reductions in ventriculoaortic pressure gradients and subjective improvements have been reported. ${ }^{28,}{ }^{29}$ After longlasting pacing the ventriculoaortic gradient was found to remain reduced even after switching from ventricular pacing to sinus rhythm. ${ }^{28}$ This observation suggests that pacing caused a change in septal anatomy. The data from this study support this idea. Because the septum is activated relatively early in right ventricular apex pacing, local mechanical load is expected to decrease, which leads to a decrease in wall mass in normal canine hearts. In this way asynchronous electric activation could be used to correct asymmetric hypertrophy. This idea is supported by recent findings of Fananapazir et al ${ }^{30}$ in a study on the effects of right ventricular apex pacing in patients with obstructive hypertrophic cardiomyopathy. These investigators found a reduction in thickness of the early activated septum of $>4 \mathrm{~mm}$ in $23 \%$ of their patients. Future studies will be required to elucidate the structural and functional relevance of the asymmetry in wall thickness in patients with asynchronous electric activation and in patients with hypertrophic obstructive cardiomyopathy.

Conclusions. These results indicate that long-lasting asynchronous electric activation of the left ventricle induces asymmetry of wall thickness. The pattern of this asymmetry is similar to the patterns of early systolic fiber stretch, as observed in previous experiments with acute ventricular pacing. The data therefore indicate that local differences in mechanical load may be responsible for local differences in myocardial growth.

We thank Ruud Kruger and Theo van der Nagel for their technical support and Vincent Schouten (Bakken Research Center, Medtronic) for his support and scientific interest during this study.

\section{REFERENCES}

1. Anversa P, Ricci R, Olivetti G. Quantitative structural analysis of the myocardium during physiological growth and induced cardiac hypertrophy. J Am Coll Cardiol 1986;7:1140-9.

2. Mann DL, Spann JF, Cooper IV G. Basic mechanisms and models in cardiac hypertrophy: part 1, pathophysiological models. Mod Concepts Cardiovasc Dis 1988;57:7-11.

3. Pfeffer MA, Braunwald E. Ventricular remodeling after myocardial infarction. Experimental observations and clinical implications. Circulation 1990;81:1161-72.

4. Little WC, Reeves RC, Arciniegas J, Katholi RE, Rngers EW. Mechanism of abnormal interventricular septal motion during delayed left ventricular activation. Circ Res 1982;65:1486-90.

5. Miyazawa K, Honna T, Haneda T, Shirato K, Nakajima T. Dynamic geometry of the left ventricle during ventricular pacing: correlation with cardiac pumping action. Tohoku J Exp Med 1978;124:261-6.

6. Curtius JM, KnueppeI S, Meschig R, Balkenhoff K, Arnold G, Loogen $F$. Left ventricular contraction pattern in left bundle branch block and its hemodynamic effects. Z Kardiol 1986;75:138-46.

7. Prinzen FW, Augustijn CH, Arts T, Allessie MA, Reneman RS. Redistribution of myocardial fiber strain and blood flow by asynchronous activation. Am J Physiol 1990;259:H300-8. 
8. Delhaas T, Arts T, Prinzen FW, Reneman RS. Regional fibre stress-fibre strain area as estimate of regional oxygen demand in the canine heart. J Physiol (Lond) 1994;477.3:481-96.

9. Badke FR, Boinay $P$, Covell JW. Effect of ventricular pacing on regional left ventricular performance in the dog. Am J Physiol 1980;238:H85867.

10. Frais MA, Botvinick EH, Shosa DW, O'Connell WJ, Scheinman MM, Hattner RS, Morady F. Phase image analysis of ventricular contraction in left and right bundle branch block. Am J Cardiol 1982;50:95-105.

11. McGowan RL, Welch TG, Zaret BL, Bryson AL, Martin ND, Flamm MD. Noninvasive myocardial imaging with potassium- 43 and rubidium-81 in patients with left bundle branch block. Am J Cardiol 1976;38:422-8.

12. Hirzel HO, Senn M, Nuesch K, Buettner C, Pfeiffer A, Hess OM, Krayenbuehl HP. Thallium-201 scintigraphy in complete left bundle branch block. Am J Cardiol 1984;53:764-9.

13. Delhaas T, Arts T, Prinzen FW, Reneman RS. Relation between regional electrical activation time and subepicardial fiber strain in the canine left ventricle. Pflügers Arch 1993;423:78-87.

14. Gomes JAC, Damato AN, Akhtar M, Dhatt MS, Calon AH, Reddy CP, Moran HE. Ventricular septal motion and left ventricular dimensions during abnormal ventricular activation. Am J Cardiol 1977;39:641-50.

15. Sahn DJ, De Maria A, Kisslo J, Weyman A. Recommendations regarding quantifications in M-mode echocardiographic measurements. Circulation 1978;58:1072-83.

16. Devereux RB, Reichek N. Echocardiographic determination of the left ventricular mass in man. Anatomic validation of the method. Circulation 1977;55:613-8.

17. Brilla CG, Tan LP, Pick R, Janicki JS, Weber KT. Remodeling of the rat right and left ventricle in experimental hypertension. Circ Res 1990;67:1355-64.

18. Mann DL, Kent RL, Cooper IV G. Load regulation of the properties of adult feline cardiocytes: growth induction by cellular deformation. Circ Res 1989;64:1079-90.

19. Komuro I, Kaida T, Shibazaki Y, Kurabayashi M, Katoh Y, Hoh E, Takaku F, Yazaki Y. Stretching cardiac myocytes stimulates proto-oncogene expression. J Biol Chem 1990;265:3595-8.
20. Sadoshima JI, Takahashi T, Jahn L, Izumo S. Roles of mechano-sensitive ion channels, cytoskeleton, and contractile activity in stretch-induced immediate-gene expression and hypertrophy of cardiac myocytes. Proc Natl Acad Sci U S A 1992;89:9905-9.

21. Swynghedauw B. Remodelling of the heart in response to chronic mechanical overload. Eur Heart J 1989;10:935-43.

22. Arts T, Prinzen FW, Snoeckx LHEH, Rijcken JM, Reneman RS. Adaptation of cardiac structure by mechanical feedback in the environment of the cell: a model study. Biophysical J 1994;66:953-61.

23. Kulbertus HE, Demoulin J-C. The left hemiblocks: significance, prognosis and treatment. Schweiz Med Wochenschr 1982;112:1579-84.

24. Abbasi AS, Eber LM, MacAlpin RN, Kattus AA. Paradoxical motion of interventricular septum in left bundle branch block. Circulation 1974; 49:423-7.

25. Noble M, Humphrey SB, Monaghan GB. Left ventricular hypertrophy in left bundle branch block. J Electrocardiology 1984;17:157-60.

26. Racovec P, Kranjec I, Fettich J, Fidler V, Pungercar D, Janezic A, Porenta M, Varl B. Localization of accessory pathways in WolffParkinson-White syndrome by phase imaging. Cardiology 1983;70:13844.

27. Swiryn S, Pavel D, Byrom E, Bauernfeind RA, Strasberg B, Palileo E, Lam W, Wyndham CRC, Rosen KM. Sequential regional phase mapping of radionuclide gated biventriculograms in patients with sustained ventricular tachycardia: close correlation with electrophysiologic characteristics. AM HEART J 1982;103:319-32.

28. Jeanrenaud X, Goy JJ, Kappenberger L. Effects of dual-chamber pacing in hypertrophic obstructive cardiomyopathy. Lancet 1992;339:131823.

29. Fananapazir L, Cannon RO, Tripodi D, Panza J. Impact of dual-chamber permanent pacing in patients with obstructive cardiomyopathy with symptoms refractory to verapamil and beta-adrenergic blocker therapy. Circulation 1992;85:2149-61.

30. Fananapazir L, Epstein ND, Curiel RV, Panza J, Tripodi D, McAreavey D. Long-term results of dual-chamber (DDD) pacing in obstructive hypertrophic cardiomyopathy. Evidence for progressive symptomatic and hemodynamic improvement and reduction of left ventricular hypertrophy. Circulation 1994;90:2731-42. 